\title{
Cancer susceptibility syndromes in children in the area of broad clinical use of massive parallel sequencing
}

\author{
Michaela Kuhlen $^{1} \cdot$ Arndt Borkhardt $^{1}$
}

Received: 19 March 2015 /Revised: 6 May 2015 / Accepted: 8 May 2015 / Published online: 16 May 2015

(C) The Author(s) 2015. This article is published with open access at Springerlink.com

\begin{abstract}
Children diagnosed with cancer are considered for inherited cancer susceptibility testing according to wellestablished clinical criteria. With increasing efforts to personalize cancer medicine, comprehensive genome analyses will find its way into daily clinical routine in pediatric oncology. Whole genome and exome sequencing unavoidably generates incidental findings. The somatic "molecular make-up" of a tumor genome may suggest a germline mutation in a cancer susceptibility syndrome. At least two mechanisms are well-known, (a) chromothripsis (Li-Fraumeni syndrome) and (b) a high total number of mutational events which exceeds that of other samples of the same tumor type (defective DNA mismatch repair). Hence, pediatricians are faced with the fact that genetic events within the tumor genome itself can point toward underlying germline cancer susceptibility. Whenever genetic testing including next-generation sequencing (NGS) is initiated, the pediatrician has to inform about the benefits, risks, and alternatives, discuss the possibility of incidental findings and its disclosure, and to obtain informed consent prior to testing.

Conclusions: Genetic testing and translational research in pediatric oncology can incidentally uncover an underlying cancer susceptibility syndrome with implications for the entire
\end{abstract}

Communicated by David Nadal

Revisions received: 1804 April 2015 / 06 May 2015

Michaela Kuhlen

Michaela.Kuhlen@med.uni-duesseldorf.de

Arndt Borkhardt

Arndt.Borkhardt@med.uni-duesseldorf.de

1 Department of Pediatric Oncology, Hematology and Clinical Immunology, University Children's Hospital, Medical Faculty, Heinrich-Heine-University, Moorenstr. 5,

40225 Duesseldorf, Germany family. Pediatricians should therefore increase their awareness of chances and risks that accompany the increasingly wide clinical implementation of NGS platforms.

What is Known:

- The proportion of cancers in children attributable to an underlying genetic syndrome or inherited susceptibility is unclear.

- Pediatricians consider children diagnosed with cancer for inherited cancer susceptibility according to well-established clinical criteria.

What is New:

- Genetic testing of tumor samples can incidentally uncover an underlying cancer susceptibility syndrome.

- Findings in tumor genetics can be indicative that the tumor arose on the basis of the child's germline alteration, (a) chromothripsis and (b) a high total number of mutational events which exceeds that of other samples of the same tumor type.

Keywords Cancer susceptibility syndrome $\cdot$ Hereditary $\cdot$ Childhood $\cdot$ Next-generation sequencing $\cdot$ Chromothripsis · Mutation rate

\begin{tabular}{|c|c|}
\hline \multicolumn{2}{|c|}{ Abbreviations } \\
\hline ALL & Acute lymphoblastic leukemia \\
\hline CMMR-D & Constitutional mismatch repair-deficiency \\
\hline CSS & Cancer susceptibility syndromes \\
\hline DGV & Database of genomic variants \\
\hline INFORM & $\begin{array}{l}\text { Individualized therapy for relapsed } \\
\text { malignancies in childhood }\end{array}$ \\
\hline LFS & Li-Fraumeni syndrome \\
\hline LOH & Loss of heterozygosity \\
\hline $\mathrm{Mb}$ & Megabase \\
\hline NGS & Next-generation sequencing \\
\hline SHH-MB & Sonic-Hedgehog medulloblastoma \\
\hline SNPs & Single nucleotide polymorphisms \\
\hline SNVs & Single nucleotide variants \\
\hline
\end{tabular}




\section{Introduction}

Until now, the proportion of cancers in children and adolescents attributable to an underlying genetic syndrome or inherited susceptibility is unclear. In the early 1990s, the inherited fraction of childhood cancer was estimated at 1$10 \%$ [29]. A recent report from the Pediatric Cancer Genome Project/St. Jude Children's Research Hospital determined an incidence of $16.0 \%$ in patients with solid tumors, $8.6 \%$ with brain tumors, and $3.9 \%$ with leukemias. The report initially focused on 23 well-known cancer predisposition genes and 8 genes that predispose to pediatric cancer with a high penetrance [47]. The most frequently affected genes included TP53, APC, and BRCA2. Additional analyses were expanded to 565 genes that are known to play a role in various steps and pathways of cellular transformation. Identified variants were classified as pathologic, likely pathologic, uncertain significance, likely benign, and benign. Taking the larger gene-set into account, the overall prevalence of an inherited mutation increased only slightly, with a pathologic or likely pathologic variant being detected in $8.6 \%$ of all patients and $4.6 \%$ of patients with leukemia. However, the spectrum of tumors sequenced was not numerically representative of the spectrum of childhood tumors, and the mutation frequencies may be skewed accordingly. In a hereditary cancer risk assessment study in survivors of childhood cancer, a genetic counselor considered $29 \%$ of the survivors as eligible for further genetics evaluation [19].

However, in the era of high-throughput sequencing in which new cancer susceptibility syndromes (CSS) and mechanisms are increasingly discovered - did we so far maybe just see the tip of the iceberg?

\section{Current clinical approach to CSS}

Pediatric oncologists consider children diagnosed with cancer and their families for inherited cancer susceptibility according to well-established criteria [20]. These comprise patientspecific constellations including (i) rare tumors commonly associated with cancer predisposition (e.g., adrenocortical carcinoma), (ii) bilateral or multifocal tumors (e.g., Wilms' tumor), (iii) cancer diagnosis at a younger than expected age (e.g., thyroid carcinoma), (iv) multiple synchronous or metachronous tumors, (v) additional conditions (e.g., axillary freckling) indicative of an underlying syndrome, and (vi) suspicious family features. These might include (a) familial clustering of the same or closely related cancers, (b) cancer diagnoses in two or more first-degree relatives, (c) tumor patterns associated with a specific cancer predisposition syndrome, (d) exceptional young age at diagnosis, (e) sibling with childhood cancer, and (f) consanguineous parents.

Li-Fraumeni syndrome (LFS) is one of the most striking familial cancer predisposition syndromes. It is clinically and genetically heterogeneous and characterized by autosomal dominant inheritance and early onset of tumors, multiple tumors within one individual, and multiple affected family members. LFS presents with a variety of tumor types with soft tissue sarcomas, osteosarcomas, breast cancer, brain tumors, leukemia, and adrenocortical carcinoma being the most common tumor types. Comprehensive surveillance protocols have been implemented and proven efficiency in terms of superior survival [46]. Table 1 lists common hereditary cancer susceptibility syndromes sorted by the underlying mechanism. The American College of Medical Genetics and Genomics and the National Society of Genetic Counselors just published the latest referral indications for cancer predisposition assessment [13]. However, due to de novo mutations, incomplete penetrance of inherited mutations, and variable phenotype/ genotype correlations, the family history may not in all cases be helpful. For example, up to $25 \%$ de novo events of TP53 mutations are reported in Li-Fraumeni syndrome [6]. In most other cases of CSS, however, the proportion of inherited susceptibility versus de novo mutations remains unknown.

\section{Personalized medicine}

With the ongoing efforts to personalize cancer medicine, comprehensive genome analyses will increasingly find its way into daily clinical routine in pediatric oncology. In the recently established German INdividualized therapy FOr Relapsed Malignancies in childhood (INFORM) project, this idea has been introduced for pediatric patients with relapsed or refractory high-risk disease without further standard of care therapy options. Individual tumor samples are characterized on the molecular level by next-generation sequencing (NGS) to establish a "fingerprint" of the tumor to identify promising targets for a successful relapse therapy [10].

Other such examples in which the detection of specific mutations has already led to a change of therapy of course also exist. Recently, a new leukemia subtype of high-risk Bprecursor acute lymphoblastic leukemia (ALL), called Ph-like ALL, was characterized. Besides its Ph- or BCR-ABL-like transcriptional profile, no translocation $\mathrm{t}(9 ; 22)$ or $\mathrm{BCR} / \mathrm{ABL}$ rearrangement, respectively, is present. Instead, multiple other genetic alterations can be detected, which are potentially druggable by tyrosine kinase inhibitors or other targeted therapies [18, 24, 36, 37]. In pediatric low-grade astrocytoma, the BRAF V600E-mutation was identified as a frequent genomic aberration activating the MAPK pathway. Tumors carrying this mutation show significantly increased BRAF and CCND1 levels [33]. Since its discovery, the BRAF V600Emutation has been described in an increasing number of pediatric central nervous system (CNS) tumors [8, 11, 40, 41]. Targeted therapies such as the BRAF inhibitor vemurafenib and MEK1/2 inhibitors are available and some encouraging examples of effective therapies even in very aggressive tumor 


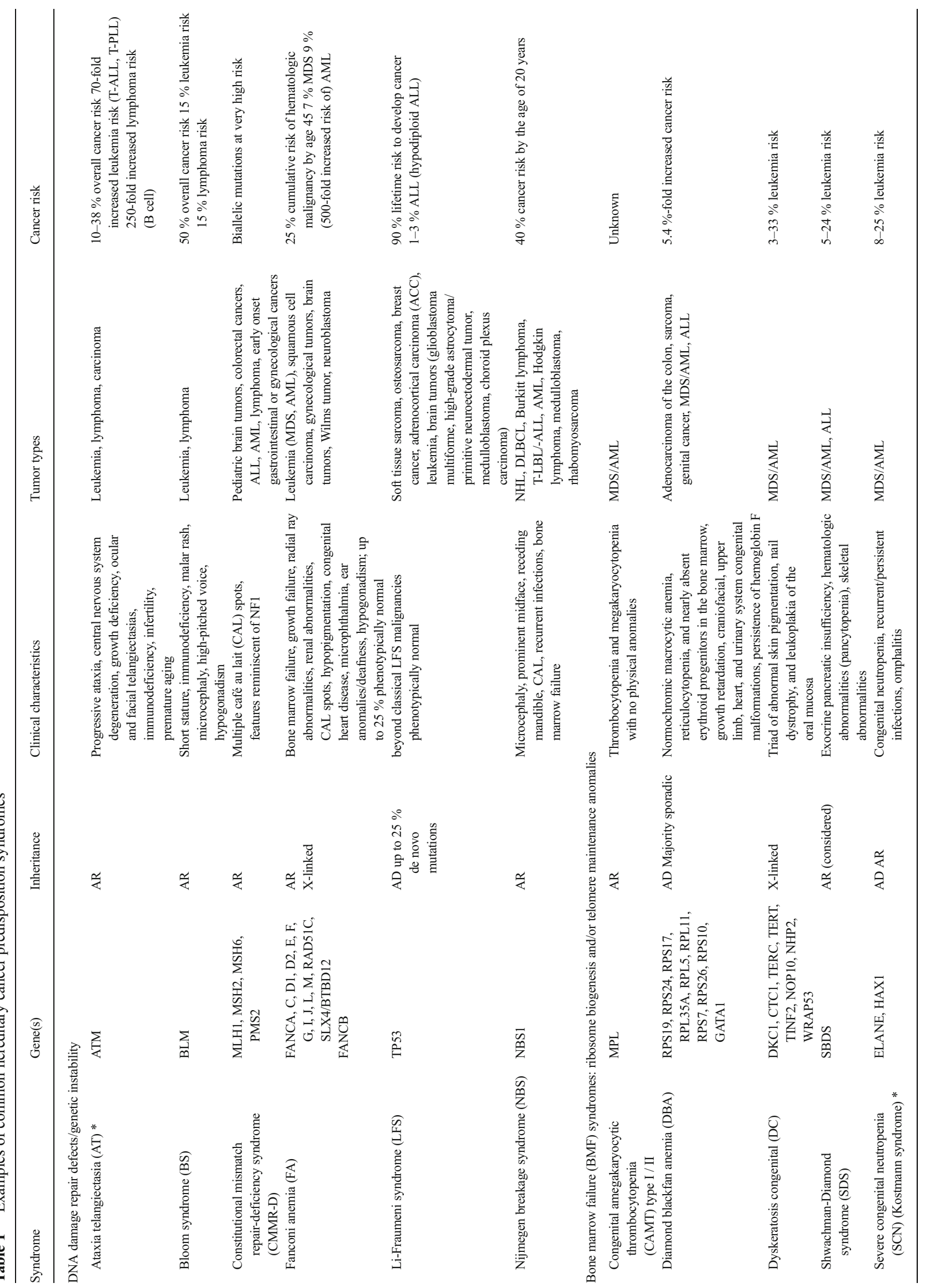




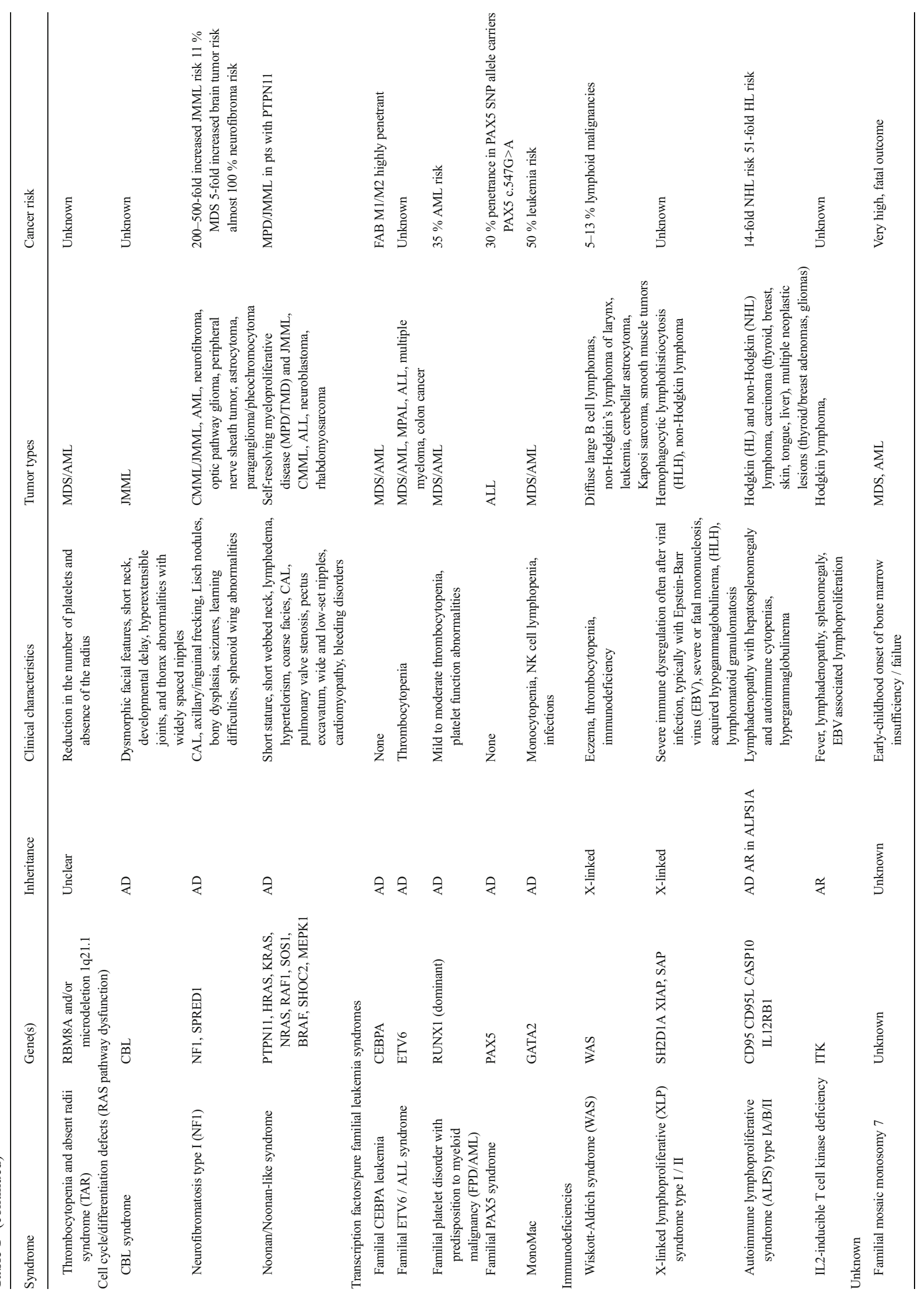




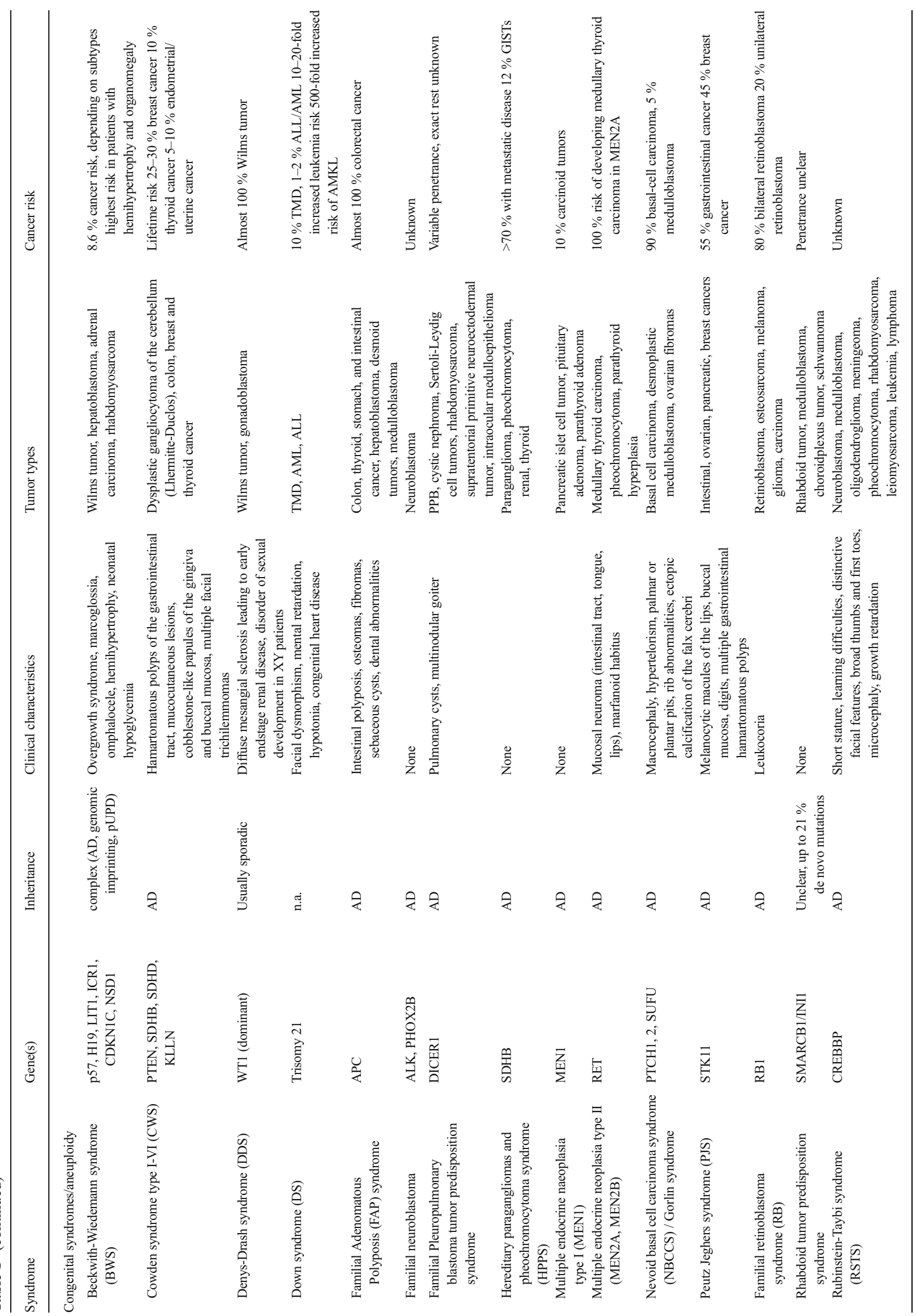




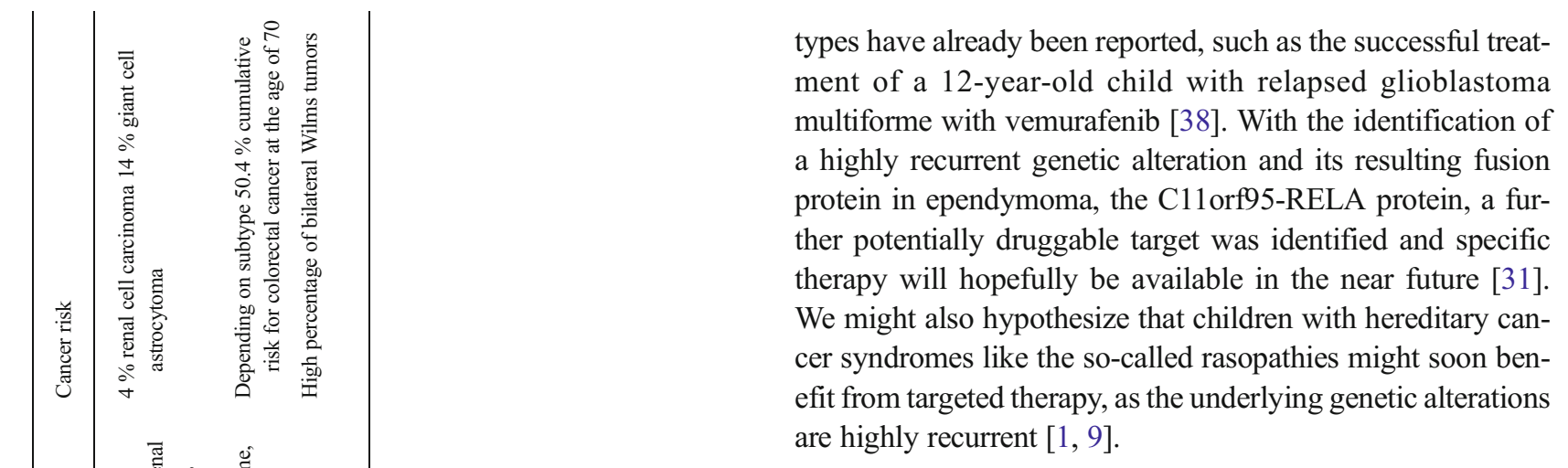

\section{Next-generation sequencing}

Due to rapid technical advances in the field of NGS, tumor (including leukemia) genomes can nowadays comprehensively be analyzed within few days. Today's state of the art in high-throughput sequencing already allows the usage of whole genome sequencing for research projects and of whole exome sequencing for daily clinical routine. However, the likelihood of identifying contemplable mutations is highly dependent on the relative ability of the sequencing approach to find these mutations. Computational processing, analyzing, and interpreting the massive amounts of data and genetic variants produced by NGS still remains challenging and requires comparisons with databases such as dbSNP and 1000 genomes project $[3,16]$. Another valuable resource in interpreting own experimental data is the ExAC browser provided by the Broad Institute at www.exac.broadinstitute.org. It meanwhile provides exome data from more than 60,000 unrelated individuals. Before definitive conclusions can be drawn, the functional consequences of identified mutations on protein structure and function often have to be demonstrated experimentally [43]. In addition, a frequent conceptual misunderstanding relates to the fact that even a mutation with profound impact on protein function does not automatically proves its pathogenicity and disease-causing effect.

Each of us carries an average of approximately 3000 single nucleotide polymorphisms (SNPs) in terms of individual SNPs. To generate a personal cancer genome signature for molecular targeted therapy, it is important to discriminate between these individual SNPs and somatic (tumor) mutations. Thus, comparing the NGS data of tumor versus germline DNA is a condition sine qua non to identify the somatically acquired genetic variants of the tumor.

However, NGS not only generates focused genetic results with precise clinical implications for treatment but also so-called incidental findings with possible, limited, or unknown clinical impact or might even uncover an underlying susceptibility to cancer and other hereditary diseases. Such incidental findings are divided into "anticipatable" and "unanticipatable" ones. The former is 
a finding that is known to be associated with the test and is possible to be found. The latter could not have been anticipated given the current state of scientific knowledge [17]. Hence, treating physicians will increasingly be faced with such incidental genetic findings and the difficulties of interpreting and reporting these results.

Moreover, the pediatric oncologist is confronted with one new situation in particular: the fact that genetic events within the tumor genome itself can point toward underlying germline cancer susceptibility. Thus, even if not initially aimed to detect a CSS, the somatic "molecular make-up" of the tumor genome may suggest a germline mutation in a CSS gene.

Up to now, there are two well-known findings in tumor genetics which can be indicative that the tumor arose on the basis of the child's germline alteration, (a) chromothripsis and (b) a high total number of mutational events which exceeds that of other samples of the same tumor type.

(a) The phenomenon of chromothripsis was first reported by Stephens in 2011 [44]. The term "chromothripsis" ("chromo" from chromosome; "thripsis" for shattering into pieces) describes the shattering of a chromosome or a chromosomal region into tens to hundreds of pieces and locally clustered reassembling of some of the genomic fragments while others are lost to the cell.

According to Stephens [44], chromothripsis is defined by six features: (1) rearrangements localized within the genome, (2) oscillating changes of the copy number profile between one and two copies, whereby (3) loss of heterozygosity (LOH) causes a copy number of one, and retaining heterozygosity a copy number of two, (4) clustering of breakpoints across the chromosome, (5) conjunction of two remote chromosome fragments, and (6) joining rearrangements between two chromosome arms with clustering at the breakpoints. Rapid oscillations between copy number states one and two within the whole or parts of the chromosome characterizes the copy number profile in case of chromothripsis.

In contrast to common theories of cancer evolution through progressive accumulation of genomic alterations such as oncogene activation and tumor suppressor loss through environmental and lifestyle factors in adults, chromothripsis as a single catastrophic event might be involved in the development of a variety of cancers in childhood. It can cause the formation of new gene fusions, disruption of tumor suppressors, and amplification of oncogenes [35, 44]. In adults, $2-3 \%$ of all cancers show evidence of chromothripsis; in bone cancers, this incidence is especially high with $25 \%$ [44]. The impact of chromothripsis on cancer gene function and cancer development in childhood has already been demonstrated for many different tumor entities, e.g., ALL, AML, ependymoma, medulloblastoma, neuroblastoma, and retinoblastoma $[4,23,26$,
28, 30, 31, 35]. In addition, chromothripsis has been associated with poor prognosis in neuroblastoma [28]. A list of pediatric tumors, in which chromothripsis has been described, is given in Table 2. Conversely, alterations in TP53 have been shown for low-hypodiploid ALL but without chromothriptic pattern [15].

(b) To provide a comprehensive landscape of somatic genomic alterations (termed mutational signatures) in cancer genomes, numerous cancers have been profiled by DNA sequencing $[2,34,45]$. The occurring genomic alterations are presumably caused by defective DNA replication or repair and exogenous or endogenous mutagen exposure and include substitutions, insertions or deletions, rearrangements, copy number alterations, completely new sequences from exogenous sources, and combinations of all these possibilities. The prevalence of such mutations is highly variable between cancer (sub)types [2, 22]. Due to extensive exposure to carcinogens, small cell lung cancer (tobacco) and malignant melanoma (ultraviolet light) show the highest somatic mutation prevalence (over 100/Megabase (Mb)). In contrast, the mutation rate in pediatric cancers is lowest $(0.1 /$ $\mathrm{Mb}$; approximately one change across the entire exome) as chronic mutagenic exposure plays a minor part in carcinogenesis in childhood [22]. An outline of mutation frequencies in various (pediatric) cancer types is given in Table 3.

Alexandrov et al. [2] described a mutational signature with very large numbers of substitutions and small indels, the latter at short nucleotide repeats and with overlapping microhomology at breakpoint junctions, termed "microsatellite instability," which is characteristic of cancers with defective DNA mismatch repair and may suggest constitutional mismatch repair-deficiency syndrome (CMMR-D) in childhood.

As was shown by Rausch et al. [35], the single nucleotide variant (SNV) rate of children with Sonic-Hedgehog medulloblastoma (SHH-MB) is clearly higher (24 tumor-specific SNVs) in the case of inherited TP53 mutations compared to sporadic pediatric medulloblastoma samples (average 5.7 non-synonymous SNVs per sample; [32]). Thus, comparing the patient's SNV with the average SNV rate of a given tumor entity, an increased mutation frequency (SNV rate) detected by NGS of the tumor again may point to an underlying CSS (Li-Fraumeni syndrome).

\section{Ethical and legal issues}

"Are our other children at an increased risk of developing cancer?" Parents of a child diagnosed with cancer frequently raise this question. Up to now, pediatric oncologists mostly 
Table 2 Examples of (pediatric) tumors associated with chromothripsis

\begin{tabular}{|c|c|}
\hline Tumor & References \\
\hline Burkitt lymphoma * & Sarova et al., Cancer Genet 2014 \\
\hline Brain tumors & - Parker et al., Nature 2014 \\
\hline - Ependymoma & - Zhao et al., Neuro Oncol 2014 \\
\hline - High-grade gliomas & -Rausch et al., Cell 2012 \\
\hline - Medulloblastoma & -Northcott et al., Nature 2012 \\
\hline \multicolumn{2}{|l|}{-Sonic-Hedgehog } \\
\hline -Group 3 & \\
\hline Hodgkin lymphoma * & Nagel et al., Genes Chromosomes Cancer 2013 \\
\hline Leukemia & - Rausch et al., Cell 2012 \\
\hline • AML & • Harrison et al., Blood 2015; Li et al., Nature 2014 \\
\hline $\begin{array}{l}\text { - ALL (iAMP21) } \\
\text { Neuroblastoma }\end{array}$ & $\begin{array}{l}\text { Ambros et al., Frontiers in Oncology 2014; Boeva et al., } \\
\text { PLoS One 2013; Molenaar et al., Nature } 2012\end{array}$ \\
\hline Osteosarcoma * & Stephens et al., Cell 2011 \\
\hline $\begin{array}{l}\text { Phaeochromocytoma (PCC) / } \\
\text { Paraganglioma (PGL)* }\end{array}$ & Flynn et al., J Pathol 2014 \\
\hline Retinoblastoma & McEvoy et al., Oncotarget 2014 \\
\hline
\end{tabular}

*Described in adult tumor samples reassure them that cancer in children usually is not hereditary but an exceptionally bad stroke of fate. However, will this statement still hold true in the future with ever-increasing knowledge about underlying cancer predisposition syndromes and inherited cancer susceptibilities in childhood?

The incidental finding of chromothripsis and its association with Li-Fraumeni syndrome in SHH-MB patients very well demonstrates the far-reaching consequences of translational research and genetic testing in pediatric oncology with its challenges for scientists, treating physicians, and the affected child and his entire family.
By detecting chromothripsis in a tumor, further genetic testing for germline p53 mutations is highly advisable as this phenomenon might be attributable to an underlying LiFraumeni syndrome. The latter obviously represents an important piece of clinical information as it will guide treatment, surveillance, and further early cancer screening programs $[21,46]$.

According to the recommendations of national and international human genetic societies and the legislation of most European countries, prior to genetic testing, the child (wherever possible) and the parents must be informed in detail, preferences as

Table 3 Examples of mutation frequencies in (pediatric) tumors

\begin{tabular}{|c|c|c|}
\hline Malignancy & Mutations (range) & Reference \\
\hline $\mathrm{AML}^{\mathrm{a}}$ & 0.37 per $\mathrm{Mb}(0.01-10)$ of coding sequence & Lawrence et al., Nature 2013 \\
\hline Ependymoma, intracranial ${ }^{\mathrm{b}}$ & $12.8 \pm 10.6$ mutations (range 5 to 34 ) per tumor & Bettegowda et al., Oncotarget 2013 \\
\hline Ependymoma, spinal cord ${ }^{\mathrm{b}}$ & $12.9 \pm 6.4$ mutations (range 2 to 23 ) per tumor & Bettegowda et al., Oncotarget 2013 \\
\hline Ewing $^{\mathrm{a}}$ & 0.15 per $\mathrm{Mb}$ of coding sequence & Brohl et al., PLoS Genet 2014 \\
\hline Glioblastoma multiforme $^{\mathrm{b}}$ & 1.4 per $\mathrm{Mb}$ & Cancer Genome Atlas Research Network, Nature 2008 \\
\hline Glioblastoma, non-brainstem pediatric & $23.5 \pm 11.2$ mutations (range $4-46$ ) per tumor & Bettegowda et al., Oncotarget 2013 \\
\hline $\operatorname{MDS}^{\mathrm{b}}$ & $3(0-12)$ mutations per sample in 104 cancer genes & Haferlach et al., Leukemia 2014 \\
\hline Medulloblastoma & $\begin{array}{l}8.3 \text { non-synonymous SNVs per sample } \\
0.35 \text { non-silent mutations per megabase }\end{array}$ & $\begin{array}{l}\text { Parsons et al., Science } 2011 \\
\text { Pugh et al., Nature } 2012\end{array}$ \\
\hline Neuroblastoma & 0.60 per $\mathrm{Mb}$ of coding regions & Pugh et al., Nature Genet 2013 \\
\hline Rhabdoid cancers & 0.19 per $\mathrm{Mb}(0-0.45)$ of coding regions & Lee et al., J Clin Invest 2012 \\
\hline Xanthoastrocytoma, pleomorphic ${ }^{b}$ & $9.5 \pm 8.5$ mutations (range 1 to 28 ) per tumor & Bettegowda et al., Oncotarget 2013 \\
\hline
\end{tabular}

${ }^{\mathrm{a}}$ Tumor samples not specified

${ }^{\mathrm{b}}$ Described in adult tumor samples 
to which findings should be reported must be assessed, and written informed consent must be obtained. This is a wellestablished standard of care for targeted molecular testing an affected individual or suspected carrier for a specific hereditary condition. However, NGS is likely, apart from the initial indication to perform it, to uncover incidental findings, such as an underlying CSS as well as non-cancer-related germline mutations (e.g., CFTR, Huntington's disease) with varying clinical importance for the patient. In order to comply with the aforementioned recommendations, this would require extensive genetic counseling of the child/parents of a child diagnosed with cancer undergoing NGS of the tumor prior to testing, which would have to encompass both incidental findings with possible, limited, or unknown clinical impact and numerous results unrelated to the indication for NGS [42]. We believe that this is highly impractical in the daily life of a pediatric hematooncologist as disclosing the diagnosis of cancer itself is overwhelming and dramatically limits the child's/parents' receptivity, and NGS of the tumor often has to be initiated at the time of diagnosis. However, whenever NGS is initiated, the treating physician has an obligation to discuss the full range of generated data and the possibility of incidental findings and its disclosure with the child/parents. Furthermore, the ordering physician is responsible for obtaining informed consent and providing preand post-test counseling. Thus, regarding the child's/parents' autonomy and both their right to access all NGS data and their "right not to know," they should be informed of the benefits, risks, and alternatives of genetic testing in detail $[5,7,12]$. When the patient/parent refuses to be informed about incidental findings, even if disclosure leads to beneficial interventions, the physician must ensure that adequate information has preceded this refusal. However, most clinicians do not have sufficient training in NGS and need to be extensively trained for clinical translation and reporting of NGS data.

In contrast to the standards for genetic testing in adults, predictive testing in pediatric patients is only recommended when the disease is associated with childhood onset and only with available effective screening and/or intervention options $[7,39]$. Refraining from predictive testing of children allows them to autonomously make this decision once they reach adulthood.

Last but not least, identifying children with hereditary cancer predispositions has immediate consequences for the entire family (siblings, parents, and extended family) [20, 25, 42]. Due to the young age of the index patient, potentially affected relatives might as well be young and yet asymptomatic. Having been tested themselves might - depending on the outcome - influence their family planning but will of course also provide an excellent opportunity to initiate early cancer surveillance programs which they will benefit from. However, genetic testing and tumor surveillance can have deeply affecting psychological consequences for the child and the family, emotional support should thus be in place for the families.
Clear legislation on returning genetic results in oncology are still missing. Lolkema et al. have thoroughly addressed the accompanying ethical, legal, and counseling challenges [25]. Comprehensive ethical recommendations on how to report research results to patients and parents are, for example, given by the American College of Medical Genetics and Genomics, the Boston Children's Hospital, the American Academy of Pediatrics, the "EURAT" (Ethical and legal aspects of whole human genome sequencing) project of the Marsilius Kolleg of Heidelberg University, and the Leopoldina National Academy of Sciences Germany [5, 12, 14, 27, 39]. However, their practical implementation in day-to-day clinical life remains challenging.

\section{Conclusions}

Genetic testing and translational research in pediatric oncology provides new and exciting insights into the evolution and pathogenesis of childhood cancer. On the other hand, it can incidentally uncover an underlying cancer susceptibility syndrome with implications not only for the child but also for the entire family. Pediatric oncologists should therefore increase their awareness of chances and risks that accompany the increasingly wide clinical implementation of NGS platforms $[42,43]$.

Acknowledgments The authors thank Dr. Jessica I. Höll for critical reading of the manuscript and editorial assistance. $\mathrm{AB}$ is supported by the German Research Consortium of Translational Cancer Research, DKTK.

Conflict of interest The authors declare that they have no conflict of interest.

Authors' contributions MK screened the literature, collected the data, and drafted the manuscript. AB revised the manuscript. Both authors read and approved the final manuscript.

Open Access This article is distributed under the terms of the Creative Commons Attribution 4.0 International License (http:// creativecommons.org/licenses/by/4.0/), which permits unrestricted use, distribution, and reproduction in any medium, provided you give appropriate credit to the original author(s) and the source, provide a link to the Creative Commons license, and indicate if changes were made.

\section{References}

1. Agarwal R, Liebe S, Turski ML, Vidwans SJ, Janku F, GarridoLaguna I, Munoz J, Schwab R, Rodon J, Kurzrock R, Subbiah V, Pan-Cancer Working G (2014) Targeted therapy for hereditary cancer syndromes: neurofibromatosis type 1, neurofibromatosis type 2, and Gorlin syndrome. Discov Med 18:323-330

2. Alexandrov LB, Nik-Zainal S, Wedge DC, Aparicio SA, Behjati S, Biankin AV, Bignell GR et al (2013) Signatures of mutational processes in human cancer. Nature 500:415-421 
3. Biesecker LG, Burke W, Kohane I, Plon SE, Zimmern R (2012) Next-generation sequencing in the clinic: are we ready? Nat Rev Genet 13:818-824

4. Boeva V, Jouannet S, Daveau R, Combaret V, Pierre-Eugene C, Cazes A, Louis-Brennetot C, Schleiermacher G, Ferrand S, Pierron G, Lermine A, Rio Frio T, Raynal V, Vassal G, Barillot E, Delattre O, Janoueix-Lerosey I (2013) Breakpoint features of genomic rearrangements in neuroblastoma with unbalanced translocations and chromothripsis. PLoS One 8:e72182

5. Burke W, Antommaria AH, Bennett R, Botkin J, Clayton EW, Henderson GE, Holm IA, Jarvik GP, Khoury MJ, Knoppers BM, Press NA, Ross LF, Rothstein MA, Saal H, Uhlmann WR, Wilfond B, Wolf SM, Zimmern R (2013) Recommendations for returning genomic incidental findings? we need to talk! Genet Med 15:854 859

6. Chompret A, Brugieres L, Ronsin M, Gardes M, Dessarps-Freichey F, Abel A, Hua D, Ligot L, Dondon MG, Bressac-de Paillerets B, Frebourg T, Lemerle J, Bonaiti-Pellie C, Feunteun J (2000) P53 germline mutations in childhood cancers and cancer risk for carrier individuals. Br J Cancer 82:1932-1937

7. Clayton EW, McCullough LB, Biesecker LG, Joffe S, Ross LF, Wolf SM, Clinical Sequencing Exploratory Research Consortium Pediatrics Working G (2014) Addressing the ethical challenges in genetic testing and sequencing of children. Am J Bioeth 14:3-9

8. Dahiya S, Emnett RJ, Haydon DH, Leonard JR, Phillips JJ, Perry A, Gutmann DH (2014) BRAF-V600E mutation in pediatric and adult glioblastoma. Neuro Oncol 16:318-319

9. Dilworth JT, Kraniak JM, Wojtkowiak JW, Gibbs RA, Borch RF, Tainsky MA, Reiners JJ Jr, Mattingly RR (2006) Molecular targets for emerging anti-tumor therapies for neurofibromatosis type 1 . Biochem Pharmacol 72:1485-1492

10. DKFZ (2015) DKFZ Inform 20 - Eine zweite Chance für krebskranke Kinder

11. Dougherty MJ, Santi M, Brose MS, Ma C, Resnick AC, Sievert AJ, Storm PB, Biegel JA (2010) Activating mutations in BRAF characterize a spectrum of pediatric low-grade gliomas. Neuro Oncol $12: 621-630$

12. Green RC, Berg JS, Grody WW, Kalia SS, Korf BR, Martin CL, McGuire AL, Nussbaum RL, O’Daniel JM, Ormond KE, Rehm HL, Watson MS, Williams MS, Biesecker LG, American College of Medical G, Genomics (2013) ACMG recommendations for reporting of incidental findings in clinical exome and genome sequencing. Genet Med 15:565-574

13. Hampel H, Bennett RL, Buchanan A, Pearlman R, Wiesner GL (2015) A practice guideline from the American College of Medical Genetics and Genomics and the National Society of Genetic Counselors: referral indications for cancer predisposition assessment. Genet Med 17:70-87

14. Holm IA, Savage SK, Green RC, Juengst E, McGuire A, Kornetsky S, Brewster SJ, Joffe S, Taylor P (2014) Guidelines for return of research results from pediatric genomic studies: deliberations of the Boston Children's Hospital Gene Partnership Informed Cohort Oversight Board. Genet Med 16:547-552

15. Holmfeldt L, Wei L, Diaz-Flores E, Walsh M, Zhang J, Ding L, Payne-Turner D et al (2013) The genomic landscape of hypodiploid acute lymphoblastic leukemia. Nat Genet 45:242-252

16. Idris SF, Ahmad SS, Scott MA, Vassiliou GS, Hadfield J (2013) The role of high-throughput technologies in clinical cancer genomics. Expert Rev Mol Diagn 13:167-181

17. Issues PCftSoB (2013) Anticipate and communicate ethical management of incidental and secondary findings in the clinical, research, and direct-to-consumer contexts

18. Izraeli S, Shochat C, Tal N, Geron I (2014) Towards precision medicine in childhood leukemia-insights from mutationally activated cytokine receptor pathways in acute lymphoblastic leukemia. Cancer Lett 352:15-20
19. Knapke S, Nagarajan R, Correll J, Kent D, Burns K (2012) Hereditary cancer risk assessment in a pediatric oncology followup clinic. Pediatr Blood Cancer 58:85-89

20. Knapke S, Zelley K, Nichols KE, Kohlmann W, Schiffman JD (2012) Identification, management, and evaluation of children with cancer-predisposition syndromes. Am Soc Clin Oncol Educ Book: 576-584

21. Lammens CR, Bleiker EM, Aaronson NK, Wagner A, Sijmons RH, Ausems MG, Vriends AH, Ruijs MW, van Os TA, Spruijt L, Gomez Garcia EB, Cats A, Nagtegaal T, Verhoef S (2010) Regular surveillance for Li-Fraumeni syndrome: advice, adherence and perceived benefits. Fam Cancer 9:647-654

22. Lawrence MS, Stojanov P, Polak P, Kryukov GV, Cibulskis K, Sivachenko A, Carter SL et al (2013) Mutational heterogeneity in cancer and the search for new cancer-associated genes. Nature 499: 214-218

23. Li Y, Schwab C, Ryan SL, Papaemmanuil E, Robinson HM, Jacobs $\mathrm{P}$, Moorman AV et al (2014) Constitutional and somatic rearrangement of chromosome 21 in acute lymphoblastic leukaemia. Nature 508:98-102

24. Loh ML, Zhang J, Harvey RC, Roberts K, Payne-Turner D, Kang $\mathrm{H}, \mathrm{Wu} \mathrm{G}$ et al (2013) Tyrosine kinome sequencing of pediatric acute lymphoblastic leukemia: a report from the Children's Oncology Group TARGET Project. Blood 121:485-488

25. Lolkema MP, Gadellaa-van Hooijdonk CG, Bredenoord AL, Kapitein P, Roach N, Cuppen E, Knoers NV, Voest EE (2013) Ethical, legal, and counseling challenges surrounding the return of genetic results in oncology. J Clin Oncol 31:1842-1848

26. McEvoy J, Nagahawatte P, Finkelstein D, Richards-Yutz J, Valentine M, Ma J, Mullighan C et al (2014) RB1 gene inactivation by chromothripsis in human retinoblastoma. Oncotarget 5:438-450

27. McGuire AL, Joffe S, Koenig BA, Biesecker BB, McCullough LB, Blumenthal-Barby JS, Caulfield T, Terry SF, Green RC (2013) Point-counterpoint. ethics and genomic incidental findings. Science 340:1047-1048

28. Molenaar JJ, Koster J, Zwijnenburg DA, van Sluis P, Valentijn LJ, van der Ploeg I, Hamdi M, van Nes J, Westerman BA, van Arkel J, Ebus ME, Haneveld F, Lakeman A, Schild L, Molenaar P, Stroeken P, van Noesel MM, Ora I, Santo EE, Caron HN, Westerhout EM, Versteeg R (2012) Sequencing of neuroblastoma identifies chromothripsis and defects in neuritogenesis genes. Nature 483: 589-593

29. Narod SA, Stiller C, Lenoir GM (1991) An estimate of the heritable fraction of childhood cancer. Br J Cancer 63:993-999

30. Northcott PA, Shih DJ, Peacock J, Garzia L, Morrissy AS, Zichner T, Stutz AM et al (2012) Subgroup-specific structural variation across 1,000 medulloblastoma genomes. Nature 488:49-56

31. Parker M, Mohankumar KM, Punchihewa C, Weinlich R, Dalton JD, Li Y, Lee R et al (2014) C11orf95-RELA fusions drive oncogenic NF-kappaB signalling in ependymoma. Nature 506:451-455

32. Parsons DW, Li M, Zhang X, Jones S, Leary RJ, Lin JC, Boca SM et al (2011) The genetic landscape of the childhood cancer medulloblastoma. Science 331:435-439

33. Pfister S, Janzarik WG, Remke M, Ernst A, Werft W, Becker N, Toedt G, Wittmann A, Kratz C, Olbrich H, Ahmadi R, Thieme B, Joos S, Radlwimmer B, Kulozik A, Pietsch T, Herold-Mende C, Gnekow A, Reifenberger G, Korshunov A, Scheurlen W, Omran H, Lichter P (2008) BRAF gene duplication constitutes a mechanism of MAPK pathway activation in low-grade astrocytomas. J Clin Invest 118:1739-1749

34. Pleasance ED, Cheetham RK, Stephens PJ, McBride DJ, Humphray SJ, Greenman CD, Varela I et al (2010) A comprehensive catalogue of somatic mutations from a human cancer genome. Nature 463:191-196

35. Rausch T, Jones DT, Zapatka M, Stutz AM, Zichner T, Weischenfeldt J, Jager $\mathrm{N}$ et al (2012) Genome sequencing of 
pediatric medulloblastoma links catastrophic DNA rearrangements with TP53 mutations. Cell 148:59-71

36. Roberts KG, Li Y, Payne-Turner D, Harvey RC, Yang YL, Pei D, McCastlain K et al (2014) Targetable kinase-activating lesions in Ph-like acute lymphoblastic leukemia. N Engl J Med 371:10051015

37. Roberts KG, Morin RD, Zhang J, Hirst M, Zhao Y, Su X, Chen SC et al (2012) Genetic alterations activating kinase and cytokine receptor signaling in high-risk acute lymphoblastic leukemia. Cancer Cell 22:153-166

38. Robinson GW, Orr BA, Gajjar A (2014) Complete clinical regression of a BRAF V600E-mutant pediatric glioblastoma multiforme after BRAF inhibitor therapy. BMC Cancer 14:258

39. Ross LF, Saal HM, David KL, Anderson RR, American Academy of P, American College of Medical G, Genomics (2013) Technical report: ethical and policy issues in genetic testing and screening of children. Genet Med 15:234-245

40. Schiffman JD, Hodgson JG, VandenBerg SR, Flaherty P, Polley MY, Yu M, Fisher PG, Rowitch DH, Ford JM, Berger MS, Ji H, Gutmann DH, James CD (2010) Oncogenic BRAF mutation with CDKN2A inactivation is characteristic of a subset of pediatric malignant astrocytomas. Cancer Res 70:512-519

41. Schindler G, Capper D, Meyer J, Janzarik W, Omran H, HeroldMende C, Schmieder K, Wesseling P, Mawrin C, Hasselblatt M, Louis DN, Korshunov A, Pfister S, Hartmann C, Paulus W, Reifenberger G, von Deimling A (2011) Analysis of BRAF
V600E mutation in 1,320 nervous system tumors reveals high mutation frequencies in pleomorphic xanthoastrocytoma, ganglioglioma and extra-cerebellar pilocytic astrocytoma. Acta Neuropathol 121:397-405

42. Scollon S, Bergstrom K, Kerstein RA, Wang T, Hilsenbeck SG, Ramamurthy U, Gibbs RA, Eng CM, Chintagumpala MM, Berg SL, McCullough LB, McGuire AL, Plon SE, Parsons DW (2014) Obtaining informed consent for clinical tumor and germline exome sequencing of newly diagnosed childhood cancer patients. Genome Med 6:69

43. Stadler ZK, Schrader KA, Vijai J, Robson ME, Offit K (2014) Cancer genomics and inherited risk. J Clin Oncol 32:687-698

44. Stephens PJ, Greenman CD, Fu B, Yang F, Bignell GR, Mudie LJ, Pleasance ED et al (2011) Massive genomic rearrangement acquired in a single catastrophic event during cancer development. Cell 144:27-40

45. Stratton MR, Campbell PJ, Futreal PA (2009) The cancer genome. Nature 458:719-724

46. Villani A, Tabori U, Schiffman J, Shlien A, Beyene J, Druker H, Novokmet A, Finlay J, Malkin D (2011) Biochemical and imaging surveillance in germline TP53 mutation carriers with Li-Fraumeni syndrome: a prospective observational study. Lancet Oncol 12: 559-567

47. Walsh M, Wu G, Edmonson M, Gruber TA, Easton J, Yergeau D, Vadodaria B, et al. (2014) Incidence of germline mutations in cancer-predisposition genes in children with hematologic malignancies: a report from the pediatric cancer genome project 